\title{
Report_It: Citizen Centric Approach towards e-Governance
}

\author{
Tehreem Qamar ${ }^{1 *}$, Narmeen Zakaria Bawany², Tehreem Hussain ${ }^{1}$ \\ 1 Department of Computer Science and IT, Jinnah University for Women, Karachi, Pakistan. \\ 2 Jinnah University for Women and FAST-National University of Computer and Emerging Sciences, Karachi. \\ * Corresponding author. Email: tehreem_qamar10@hotmail.com \\ Manuscript submitted January 10, 2018; accepted March 8, 2018. \\ doi: 10.17706/ijeeee.2018.8.4.212-218
}

\begin{abstract}
Report_it is a smart city service application implementing service oriented architecture. It is an issue reporting app which allow citizens to report municipality issues like garbage heaps, broken roads, damaged street lights, out of order traffic signals etc. either via web or mobile directly to the concerned department and equips the government or the administration (concerned department) to regularize \& schedule its settlement. Once the reported issue goes under the settlement pipeline; the citizen is kept updated about its progress. Furthermore it also facilitates the government to run campaigns or and monitor them effectively. It involves three stakeholders and provides them applications according to their requirements (reporter/citizen, administration/government and worker/resolver). Be it is reporting a new issue or comment /vote for an existing issue, this interface attempts to add a social dimension on both front ends and paves the way for establishment of communication between the sufferer and the reliever.
\end{abstract}

Key words: E-governance, open model, Smart city application.

\section{Introduction}

SMART CITY is a concept which is based upon the ideology of a lifestyle where daily routine activities such as, purchasing grocery or clothes, paying bills, ordering food, having news updates etc. are carried out via ICT (Information and Communication Technology) infrastructure [1], [2]. Smart city evolution brings myriad of opportunities for the developers to develop different applications that offer smart city services. This paper is aimed at presenting a smart city service that is a two way communication platform for the smart city people i.e. government and the citizen via open data model proposed in [3].

Report_it is a solution that is dealing with the problem that numerous people face in order to report the municipality issue as when it happened. It is basically a kind of e-governance solutions which allows citizens to report from their comfort level i.e. either via desktop or mobile app and allows the government to take actions digitally according to the nature of complaint and situation. The objective of e-governance are similar to the objectives of good governance but the strategic objective of e-governance is to support and simplify governance for all parties; government, citizens and businesses[4] E-governance is a way out to reduce the operational cost while ensuring a level of excellence in addressing citizen problems. There are numerous applications available that are providing more or less same functionality, but this solution differs in a way that it is providing different applications for different type of users and enables the government in running drives effectively.

It is an employment of smart city design [3] implementing service oriented architecture. It aids zone wise implementation of smart city service that ensures quality of service as discussed in [3]. This zone wise 
service is decided to be provided by creating individual websites addressing issues for a specific zone. This application attempts to negate the fact that smart city may require hefty amount for installation of such systems and provides a cost effective solution to the concerned authorities. Providing data via web service conforms the security of data and also make it available for variety of users. This solution is based upon the inspiration and motivation taken from "ImproveMyCity platform[5]" and consist of combination of web and mobile applications enabling its users to report issues directly to the administration and also empowering administration to highlight their performance without applying any extra effort.

Major contributions of this paper are;

- A citizen centric approach is proposed to improve and sustain harmony of the city

- Implementation of a service oriented model for e-governance that not only allows reporting of complaint rather effective management of the tasks and stages involved therein.

A time efficient and secure way of concluding social drives successfully is proposed along with creating a proper MIS for the event.

\section{Related Work}

According to [6] leaders will one day combine technological skills and social innovation to create a smarter world comprising smart cities. To make our cities and communities smarter, we need to look for information that aid in making connections between citizen and government. ImproveMyCity platform[5] supported by the project PEOPLE (Pilot smart urban Ecosystems leveraging Open innovation for Promoting and enabLing future E- services) offers this type of application via Joomla Extension. It provides a citizen-government collaboration platform that includes web based portal for allowing citizens to report issues from desktop PCs, an android application and a web based administrative infrastructure for the governmental agencies. FixMyStreet [7] platform empower people and build their capacity as citizens, it allow citizens to Report, view, or discuss local problems. FixMyStreet is available as a desktop and mobile website, and mobile apps .It uses Amazon EC2 services. The BOS:311[7], Houston311 [8], NYC311[9], San Antonio 311[10] app helps residents improve City neighborhoods, enabling residents to improve their neighborhoods by reporting non-emergency issues. The reports are automatically fed into the City's work order system so that they can be tracked and assign to city departments for settlement.

\section{User Characteristics}

The system comprises of three types of users;

Complainer: The one who can report complaints, view list-based/ map based issues, comment and votes.

Administrator: Administer of each zone that can send the complaint in the resolution pipeline and can create any drive with a team of workers.

Worker: The employees other than administrator and are the real actors to resolve complaints. They can view the tasks assigned, the team members and can submit their feedback.

\section{Description}

Report_it is comprised of several components. It includes Web application for administrator, web and mobile application for citizen/ complainer, mobile application for worker/ solver and Web APIs to implement functionalities for all. In this section every component is described in detail.

\subsection{Application for Administrator}

The administrator is the person who is responsible to take respective action whenever a complaint is reported or to initiate any drive. Although the administration is provided to the whole city but it used zone level architecture i.e. each zone is headed by an administrator. Report_it offers a web application that is to 
be used by each administer. The general functions include:

- Manage/ handle the complaints/ feedback received from the citizen/ complainer/ solver/ worker, managing includes assignment of complaint to worker(s).

- Filtering of complaints against its priority level, complainer, area

- Analysis of the department via chart view

- Assignment of complaint to any worker/ solver

- Formation of a drive/ campaign

- Managing running drives/ campaign

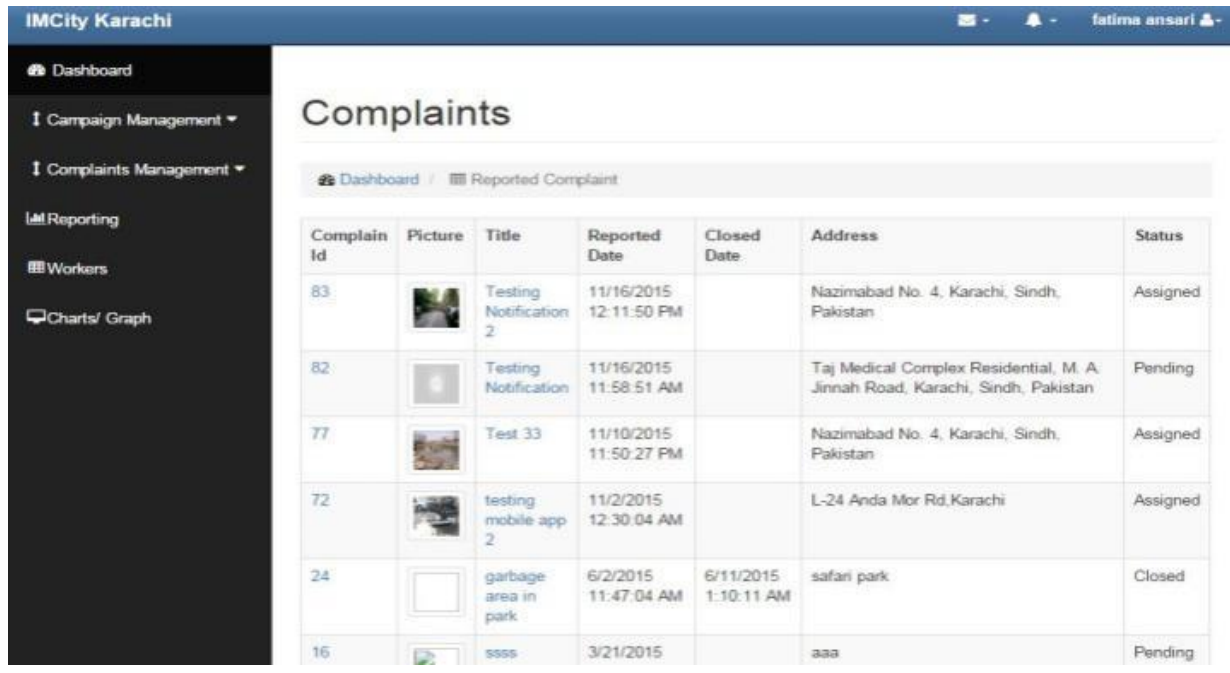

Fig. 1. Complaints reported to particular department.

The proposed system also contains a web application that offers supervision of all zones intended to be used by the owner of the city. It includes the functionality of monitoring the entire process of complaint management.

\subsection{Application for Complainer}

Complainer is the person who is allowed to submit any complaint. Two modes have been provided for it i.e. web and mobile as shown in Fig. 2 and Fig. 3 respectively. It comprises features described below; however the mobile app offer advantages of its functions:

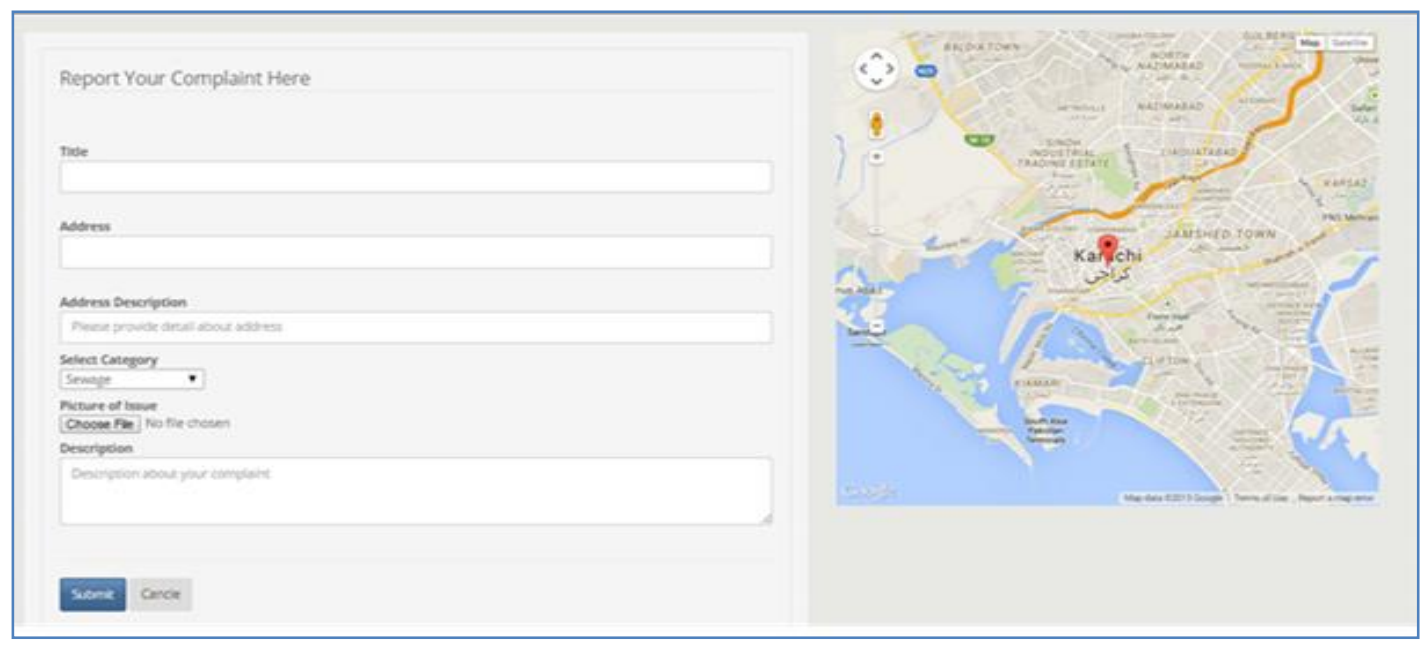

Fig. 2. Complaint lodgment via web. 


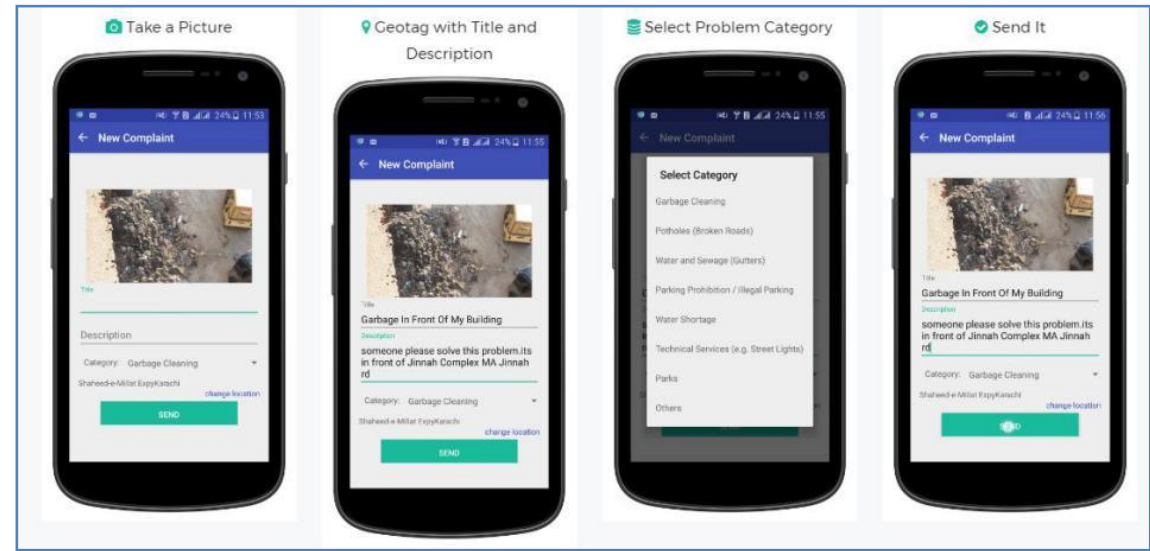

Fig. 3. Complaint reporting via mobile phone.

- Creating its account: Each user requires its account to submit any complain so that integrity of the complainer is preserved.

- Submit a complaint: The user can submit any complain by providing the issue title, location, department it can associate.

- View all reported complaints as a list and over map: The user is enabled to view all complaints in a form of list or over the map as markers.

- Comment over any complaint: Besides submitting a complaint a user can comment on any other reported complaint to make it more powerful

- Up voting any complaint: The up voting of any complaint results in increase of its priority, any registered user can up vote it.

- Maintaining its profile: A user is also capable of maintaining its profile.

\subsection{Application for Worker}

The complete process of this complaint management system will be discussed in the next section and it requires an application for the worker too to submit their feedback on run time without any delay. The features of this application include:

- Registration: An authenticated registration to the system as a worker.

- Feedback Submission: The worker is able to send feedback in the form of the picture if required to ensure that the problem is solved

- Commenting: The worker can also comment on any complaint

- View his assigned complaints/ campaigns

\section{Process}

Report_it system has two main functions: one is; to effectively manage complaints and second is; to efficiently run and track any drive or campaign.

The process of lodging a complaint is as simple as it is mentioned in [3] [4] [5], the complainer only needs an account through which he becomes able to lodge a complaint. The reported complaint then goes directly to that department which complainer has chosen at the time of reporting. The location of the issue/ complaint is automatically captured via GPS if it is reported via mobile as shown in figure 2 otherwise the complainer has to explicitly select the location from the marker provided.

Once a complaint is reported; it is assigned a status of Pending by default as shown in figure 4, then the administrator of the concerned department will be allowed to assign worker/s to it that can resolve the complaint. As the workers are assigned to the complaint the system forces the administrator to change the status of the complaint to Acknowledged. 


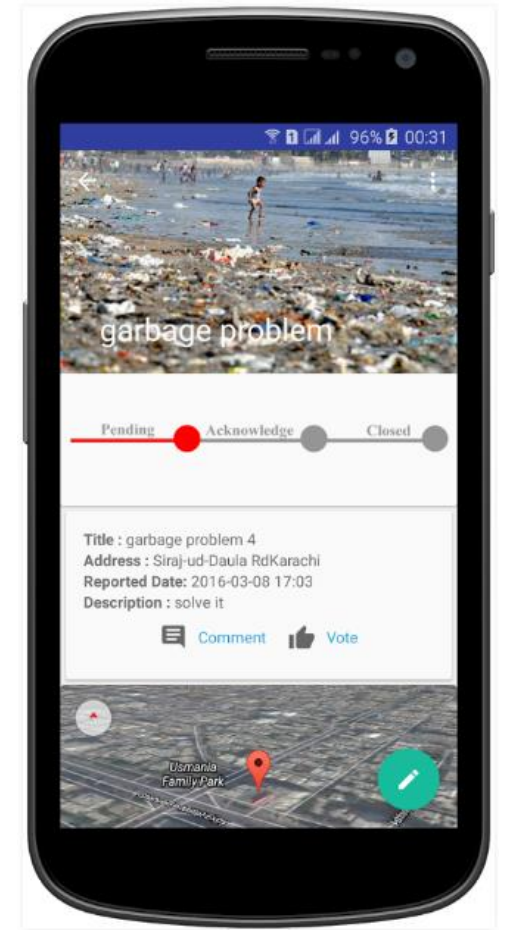

Fig. 4. Complaint status.

When the complaint's status changed to acknowledged, the complainer is notified that the reported complaint is now under process while the assigned worker is notified that now he has to resolve that complaint. As the worker report its feedback; the administrator then after analyzing, change the status of the complaint to close proceeded with generating a notification to the complainer that the complaint has now processed and closed.

The second function of this system allows the administrator to derive campaigns through it and track its progress. Once the administrator creates a drive/ campaign that also involves workers, the workers get notified via their mobile app and will be tracked via GPS.

\section{Implementation}

The system developed satisfies the Zone Level architecture proposed in [3] i.e. each department/section is provided with its own site to deal with the complaints pertained to it and a main site design for the administrator of city/company that can view the overall situation of the city/ company. This is achieved via web services; each application described in section 4 is consuming these APIs. Depending upon the functionality provided these web services vary according to the requirements of application.

\section{Deployment and Customization}

Report_it has the ability to be deployed over any large organization located within a city. It is developed as generic in nature irrespective of any particular domain. It was made completely fit for city administration but it can however be customized and installed in different sectors too; whether it is about managing a housing society, a hospital, university campuses or a whole city. It allows its users to deploy the system according to their requirement. Some practical use cases are as follows:

\subsection{Use Case - Housing Society}

The function of housing societies is somewhat like a small city; their needs are more or less equal to an urban city and therefore have to be managed in the same way. Report it system allows the management to 
create their own management hierarchical structure, their departments, workers that provide their residents an ease with an effective complaint management system.

\subsection{Use Case - University Campus}

This system helps the university to effectively manage complaints raised by either students or parents or can be from teachers no matter how many campuses it has. The university administration will be allowed to install the system according to their management hierarchy while parents and students can use the mobile application with little customization.

\subsection{Use Case - Hospitals}

Many hospitals lack in providing support to its visitors, this system allows them to provide a competent base of collecting feedback; moreover facilitates the hospital to handle non-emergency issues efficiently.

\section{Summary}

Basically, the idea of citizen government collaboration is based upon the concept of e-governance which emphasizes and ensures that a good level of flexibility and efficiency can be achieved by de-centralizing responsibilities and processes; and has already been very well developed in ImproveMyCity[11] platform. This solution provides similar functionality in a more simple yet customized and convenient way richly equipped with standalone applications for every type of it's users to perform their tasks effectively. The system also allowed the government/ administration to run drives and track them effectively. What makes this application exciting is it can easily be customized and installed at any organization catering to the specific needs and also helps to track the performance of workers around.

\section{References}

[1] Chourabi, H., Nam, T., Walker, S., Gil-Garcia, J. R., Mellouli, S., Nahon, K., Pardo, T. A., \& Scholl, H. J. (2012). Understanding smart cities: An integrative framework. Proceedings of the Annual Hawaii International Conference on System Sciences (pp. 2289-2297). Hawaii: Learned Information.

[2] Hall, R. E., Bowerman, B., Braverman, J., Taylor, J., \& Todosow, H. (2000). The vision of a smart city. Proceedings of the 2nd International Life Extension Technology Workshop: vol.28. (p. 7). Paris, France: Learned Information.

[3] Bawany, N. Z. (2015) Smart city architecture: Vision and challenges. International Journal of Advanced Computer Science and Applications, 6(11), 246-255.

[4] Basu, S. (2004). E-government and developing countries: an overview. Int. Rev. Law, Comput. Technol., 18(1), 109-132.

[5] Tsampoulatidis, I., Box, P. 0., \& Box, P. O. (2013). Improve my city - An open source platform for direct citizen-government communication. Proceedings of the 21st ACM International Conference on Multimedia: Vol. 26. (pp. 839-842). New York, USA: Learned Information.

[6] Kanter, R. M., \& Litow, S. S. (2009). Informed and Interconnected: A Manifesto for Smarter Cities (Work. Pap. No. 09-141). Cambridge: Harvard Bus. Sch. Gen. Management.

[7] FixMyStreet. (2017). Retrieved from the website: https://www.fixmystreet.com/

[8] Houston311.org. (2017). Retrieved from the website: http://www.houstontx.gov/311/

[9] 311 | City of New York. (2017). Retrieved from the website: http://www1.nyc.gov/311/

[10] 311 City Services. (2017). Retrieved from the website: http://www.sanantonio.gov/Commpa/cityservices

[11] Improve My City. (2017). Retrieved from the website: https://www.improve-my-city.com/ 
Tehreem Qamar is an M.S. student at NED University of Engineering and Technology, Karachi, Pakistan. Her research interests include machine learning, semantic web and human computer interaction. In 2015, she graduated from Jinnah University for Women with first position and currently working there as a lecturer.

Narmeen Zakaria Bawany is a Ph.D. scholar in computer science at the National University of Computer and Emerging Sciences, Karachi, Pakistan. She has served as a director of computer science and IT Department, Jinnah University for Women for 12 years. She has over 15 years of teaching experience at graduate and under graduate level. She has supervised many under graduate projects and had also received funding from ICT R\&D for under graduate projects. Her research areas include human computer interaction, semantic web, cyber security and software defined networking.

Tehreem Hussain is an M.S. student in computer science at the National University of Computer and Emerging Sciences, Karachi, Pakistan. She has done her bachelor's in computer science from Jinnah University for Women, Karachi Pakistan in 2015. She has been working as a lecturer in computer science and IT Department, Jinnah University for Women for one year. She also worked as a freelance developer and designer. Her research interests include human computer interaction, software engineering and software design and architecture. 